\title{
Research on Electric Heating Technology In-situ Oil Shale Mining
}

\author{
Yi Pan, Jingming Zhang, Xu Wang, Shuangchun Yang \\ (Liaoning Shihua University, Fushun, Liaoning, China 113001)
}

\begin{abstract}
The oil shale resources are very abundant with its reserve three times as much as world's proven oil reserve. However, by the limitations of traditional technology and mining methods, the development of oil shale technology is restricted to a great extent. Now researchers are studying the in-situ retorting technology through heating the underground oil shale directly. Then the released oil and gas will be collected on the ground. Among them, electric heating technology is more mature compared with others. In this paper, the oil shale's physical properties are presented in detail. At a high temperature, the oil shale will be cracked as the generation of lots of pores and fractures, which improves the permeability of oil shale fundamentally and creates good conditions for the output of oil and gas. Meanwhile, some of the most advanced technologies of electric heating process around the world will be discussed as well. By contrast, ICP has greater advantages over other technologies in environment protecting, cost and product. After comprehensive analysis, the development trend of future electric heating technology will be forcasted in this paper.
\end{abstract}

Keywords: - oil shale, shale oil, ICP technology, electric heating, in-situ retorting

\section{INTRODUCTION}

As the increasing International crude oil prices, energy issues have gained great importance for most countries. It is predicted that the global oil demand will grow at an annual rate of $1.9 \%$. In accordance with the petroleum's consumption rate, the world's proven crude oil reserves can only support the current oil consumption level for 45 years and that of natural gas is 66 years. Therefore, it is imperative to seek a substitute for oil in order to make it less dominant.

By the year of 2005, the published statistics indicated that the sum of the proven shale oil reserves in 37 countries were about 410 billion tons, nearly 3 times as much as that of oil in the world which was 160 billion tons. Given the fact that most of the resources of oil shale are buried deeply (over 500m underground), traditional technology achieve the pyrolysis of oil shale by the utilization of carbonization equipment on the ground to generate shale oil. However as its defects, traditional technology requires high costs and large land. Also the immaturity of the technology leads low oil recovery rate and serious pollution, etc. Now researchers are researching in situ mining technology through heating the underground oil shale directly, and then release the acquired hydrocarbons to the ground.

The technology of electric heating is more mature than others among current heating technologies. This paper describes the characteristics of oil shale and the electric heating process firstly and then its key technologies are described in detail. It also summarizes the characteristics and development trend of electric heating technology, providing reference for researchers in related field.

\section{Characteristics OF OIL SHale}

\section{A. Concept of oil shale}

Oil shale, also called kerogen shale, dense with its color from light grey to dark brown, is a kind of combustible sedimentary rocks whose calorific value is $4.18-167 \mathrm{gwJkg}$. Oil shale is consisted of minerals and organic matter $(10 \%-60 \%)$. Heated to $500^{\circ} \mathrm{C}\left(\right.$ without air) or $1000^{\circ} \mathrm{C}$, it could be used to produce shale oil and combustible gases. (3.5\%-15\%) The permeability, porosity, thermal conductivity of natural oil shale are very low, but its specific heat capacity is larger than other minerals. Its physical parameters are shown in table 1[1].

\begin{tabular}{|c|c|c|}
\hline parameter & unit & oil shale \\
\hline thermal conductivity & $\begin{array}{l}W-m^{-1} \cdot K^{-1} \\
J-g^{-1}-K^{-1}\end{array}$ & 2.5 \\
\hline thermal coefficient & $\mathrm{kg} \mathrm{m}^{2}$ & $2000^{-}$ \\
\hline density & & $2500^{-}$ \\
\hline
\end{tabular}




\section{B. Moisture content of oil shale}

The humidity of oil shale usually represents the moisture content in oil shale. In industry, the humidity of oil shale has great influence on its mining, processing and combustion. From the current research, moisture content of oil shale is between $1.07 \%$ and $6.24 \%$, and has not exceeded $10 \%$, as shown in table 2 [2].

\begin{tabular}{|c|c|c|c|c|c|}
\hline deposit & country & moisture & deposit & country & moisture \\
\hline Fu Shun & \multirow{6}{*}{ China } & $4.45 \%$ & IRA & Brazil & $3-52 \%$ \\
\hline DaLianhe & & $5.7 \%$ & Freitas horse & Australia & $0.1-23 \%$ \\
\hline Lue Zigou & & $1.07 \%$ & Alberta & Canada & $1.6 \%$ \\
\hline Jin Zhou & & $6.33 \%$ & KeWuer & America & $4 \%$ \\
\hline $\begin{array}{l}\text { Yao } \\
\text { Jie }\end{array}$ & & $2.34 \%$ & The Baltic Sea & Russia & $10.1-15 \%$ \\
\hline Yao Moshan & & $2.75 \%$ & Kinshasa & Zaire & $2.7 \%$ \\
\hline
\end{tabular}

\section{Porosity and permeability of oil shale}

Oil shale porosity decreases while the content of organic matter increases. Therefore, the porosity depends on its uniformity of mineral composition, organic matter content and composition, nature and quantity. Normally, the porosity of every single-layer of oil shale in the same stratigraphic units varies. Table 3 shows the porosity of oil shale deposit in different layers in Estonia's [3].

\begin{tabular}{|c|c|c|c|}
\hline \multicolumn{4}{|c|}{ Chart 3 Porosity of Astonia Oil Shale } \\
\hline oil shale layer & composition & Organic matter content $(\%)$ & Porosity $(\%)$ \\
\hline F & Gray matter & 39.4 & $23.7-31.8$ \\
\hline$E$ & Gray matter & $47.1^{-1}$ & $13-15.1$ \\
\hline $\mathrm{D}$ & mud & 27.1 & $1.5-28$ \\
\hline $\mathrm{C}$ & Gray matter & 37.9 & $5-24.3$ \\
\hline $\mathrm{B}^{-}$ & Gray matter & $49.2^{-}$ & $13.5-22$ \\
\hline A & Gray mattera mud & 35.3 & $16.4-24.8$ \\
\hline
\end{tabular}

The porosity of oil shale changes when temperature rises during thermal processing. For example, the porosity of the Green River shale is about $10.5 \%$. When the oil shale is heated to $510^{\circ} \mathrm{C}$, the porosity increases to $13.3 \%$, and when heated to $815^{\circ} \mathrm{C}$, it increases to $24.8 \%$. As the volume increases, the permeability coefficient is significantly improved, as shown in Figure 1[4].
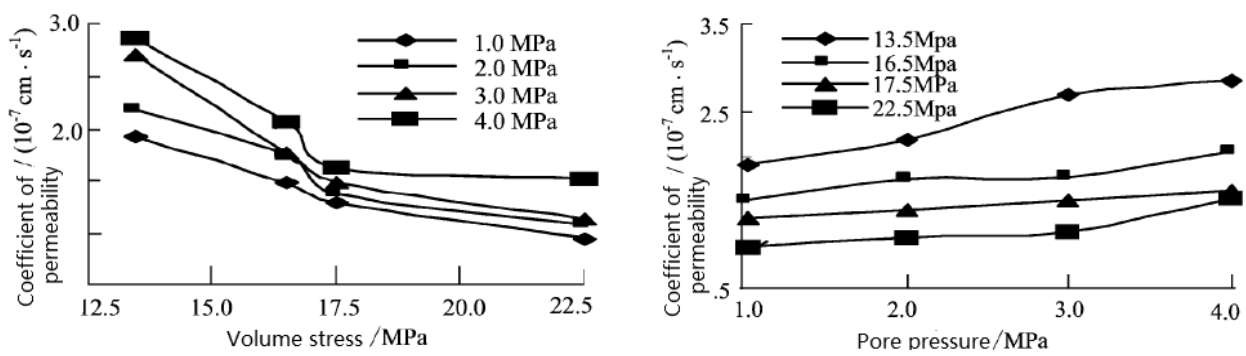

Fig. 1 coefficient of permeability under different temperature 


\section{Pyrolysis characteristics of oil shale}

In addition, after being heated to a high temperature, pyrolysis characteristics of oil shale increase significantly, shown as a loss of $15 \%$ of its overall weight. Figure 2 reveals the oil shale's pyrolysis characteristics with its temperature from $380^{\circ} \mathrm{C}$ to $500^{\circ} \mathrm{C}$, and TG and DTG changes from $20^{\circ} \mathrm{C}$ to $1000^{\circ} \mathrm{C}$. [5]This shows electric heating technology significantly reduces the difficulty of in-situ mining.

Relationship between temperture and TG

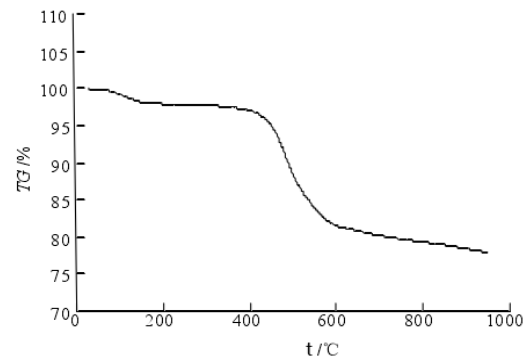

Relationship between temperature and DTG

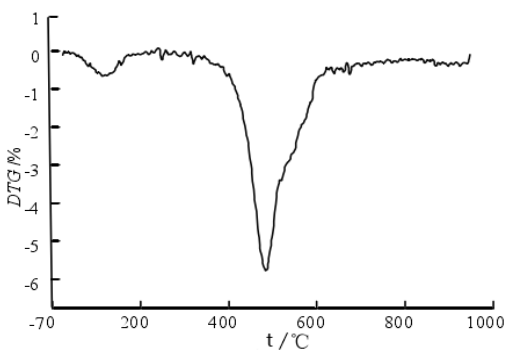

Fig. 2telationship between temperature and TG(DTG)

The first paragraph under each heading or subheading should be flush left, and subsequent paragraphs should have a five-space indentation. A colon is inserted before an equation is presented, but there is no punctuation following the equation. All equations are numbered and referred to in the text solely by a number enclosed in a round bracket (i.e., (3) reads as "equation 3"). Ensure that any miscellaneous numbering system you use in your paper cannot be confused with a reference [4] or an equation (3) designation.

\section{OVERVIEW OF ELECTRIC HEATING TECHNOLOGY}

The main methodology of electric heating technology is as following: First power is transferred to the electric heater mounted underground in the well bore to heat the well. Then the target seam of oil shale is heated as the power conducted to there. Light shale oil will be produced through chemical reactions when the oil shale is heated to a temperature as high as required. And the products will be pumped to the ground thereafter. Considering different technologies required the combination of heat wells and production wells can be divided into two categories, as shown in Figure 3.
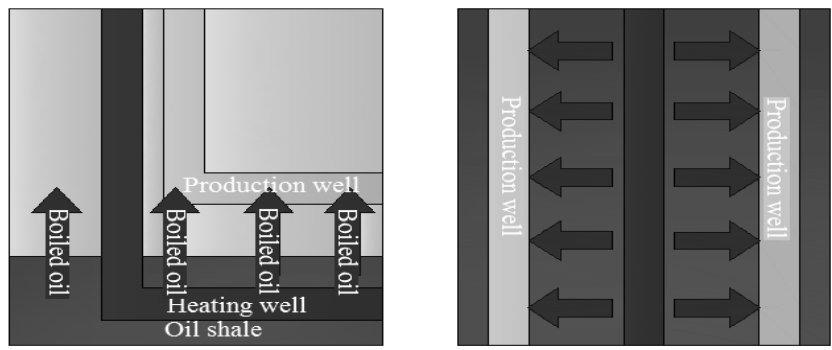

Fig. 3 combinations of heating and production wells

\section{A. ICP technology of Shell}

After a large amount of researches both in laboratory and during production practice, Shell has proved that it is commercially feasible to exploit oil through heating target oil shale by electric heater mounted underground in the wellbore. Through thermal simulation in laboratory and pilot projects in practice, the ICP has been developed after decades of hardwork. A variety of heating methods have been investigated such as steam injection, installation of underground heater, and studied the combination of wells in different depths, for the heating, production, testing, and drainage respectively. To make a conclusion: the technology of electrical heating is the most economical and environmentally friendly one [6].

\section{ICP principle}

Many wells would be drilled at first (inter well distance should be less than $20 \mathrm{~m}$ ), and then heat oil shale by means of electric heating technology, the shale oil would be collected thereafter. Every well has its own functions, the main types of wells are as following: $\$$ Heating wells provide heat continually; 2Droduction wells collect and transport oil and gas to the surface; 3Monitoring wells are mainly used for monitoring temperature 
and pressure, in order to determine the scope of the pyrolysis of oil shale. Various types of well distribution are shown in Figure 4.

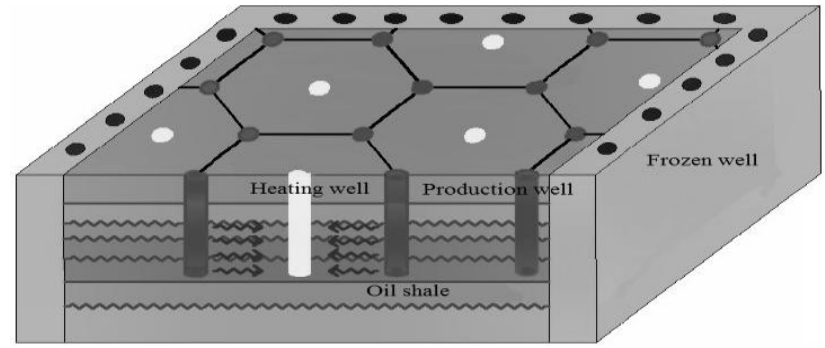

Fig 4 Various types of wells

\section{Frozen wall system}

Frozen-wall technology is used in order to prevent groundwater from flowing into the oil shale zone. A series of wells would be drilled around the mining area. Then cooling fluid with a temperature of $-45 \mathrm{~F}$ will be injected to make groundwater freeze as a "frozen wall" with a purpose of protecting the groundwater from being contaminated. After that, all the groundwater in the mining area will be pumped away to reduce energy consumption in the process of heating. [7]Frozen wells and other wells are shown in Figure 5.

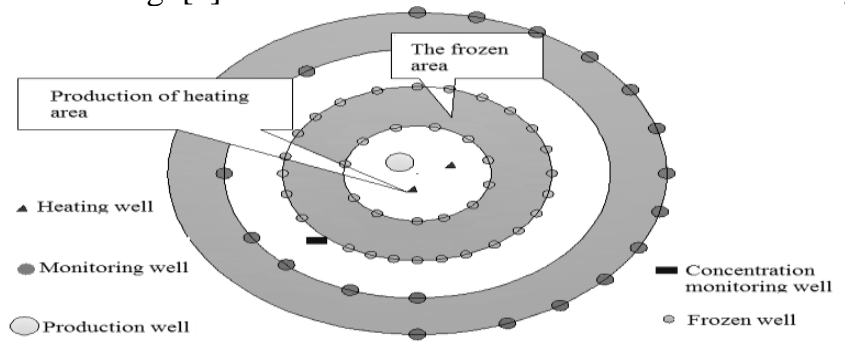

Fig 5 Frozen wells and other wells

\section{Electic heating system}

Using many short distance downhole electric heater ,ICP technology heats stratum for 3-6 years to $340^{\circ} \mathrm{C}$ making the oil shale kerogen begin to converse. Experiment has proved that the liquid recycling efficiency is greater than $60 \%$ which was measured by Fischer. The oil API is $25-40$, and the energy gain is almost $3[8]$.

After the frozen wall is built, workers will drill 70-100 heating wells, and install a vertical heater with no electrode in every hole of the wells. Every three heaters use a three-phase $\mathrm{Y}$ circuit in conductive configurations and a neutral connection on the bottom. The heater is placed in the target ore belt in three neighboring wells. A ICP heater includes three parts: overlying layer, target ore belt and electrical contact segments. As shown in Figure 6.

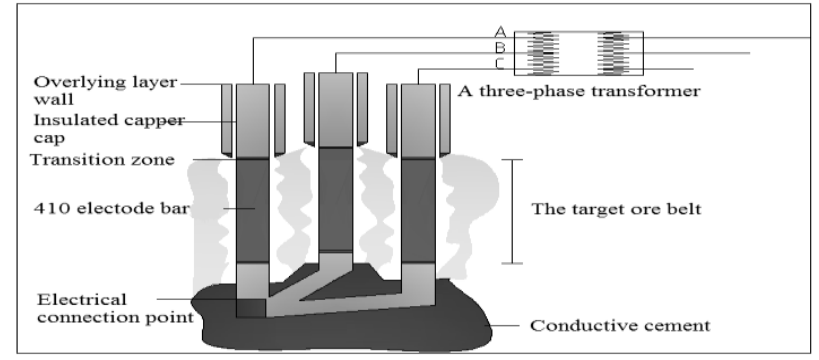

Fig 6 diagrammatic of electric heater

\section{Advangtage}

ICP technology provides a solution of high cost; improves utilization efficiency of the resource; reduces the contamination to the environment; occupies no land; makes the transformation ability of kerogenthe nearly 2 times as much as that of other methods; produces product which is almost light oil, such as kerosene and diesel, without the need of complex post-processing.

Nevertheless, the process also has some disadvantages: Electric heating is complex. Heating elements and their power are small, and can only affect a limited area; Hydrocarbon movability remains low, leading to low recovery rate. 


\section{B. Voltage fracturing technology of Exxon Mobil}

Exxon Mobil is also studying the conversion process of underground oil shale. Electrofrac (voltage crack) process fractures oil shale through hydrofracture, and then injects conductive prop pant into the crack in order to form an electrical heating element. Energy is transmitted to oil shale, making the kerogent transform into oil and gas, and then taken out by normal means, as shown in Figure 7.

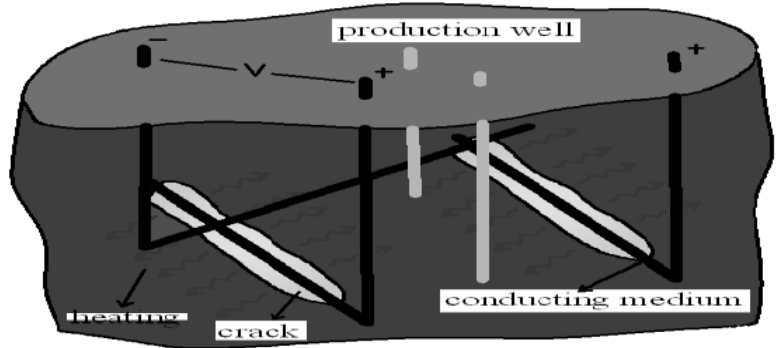

Fig 7 diagrammatic of conversion process of oil shale

\section{Principle}

Through hydraulic fracture, the formation is fractured. The eventual supporting slit width is about 3 $\mathrm{mm}$, and the total length can reach hundreds of meters or more. To prevent the crack from as the pressure declines after the pump truck stops, sands whose size is several times larger than their counterparts underground, will be injected mixed with the fluid.

\section{Frozen wall system}

Like the technology used by Shell, Exxon also needs some tactics for in situ technologies to prevent the intrusion of formation water and protect the formation water from being contaminated by carbohydrate and other components generated. The principle is shown in figure 6:

\section{Electric heating system}

Different with Shell's technology, Exxon fractures oil shale first through water power in horizontal wells, and then injects a conductive material into the cracks to form a heating unit, which will convert the in-situ oil shale to heat the in situ oil shale, as shown in Figure 8.

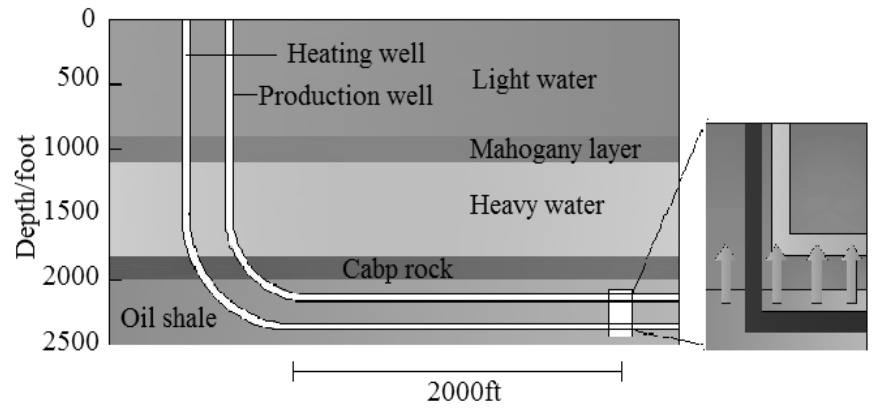

Fig 8 diagrammatic of Electric heating system

\section{Advangtage}

(1) The permeability of shale increases by using this technology, making it easier to exploit dense oil shale; (2) Na2CO3 would be produced as a byproduct; (3) The thermal efficiency will be improved effectively.

\section{IEP Geothermic fuel cell}

This technique uses a kind of geothermal fuel cell to transform kerabitumen into shale oil without burning any substance, and also offers electric energy to the external.

\section{Principle}

IEP places high-temperature fuel cells on oil shale reservoir in order to heat target stratum. When it is heated, hydrocarbons flucid and gas will be released into collecting well. After being collected, a part of gas will return to the fuel cells and the rest is for sale. After initial heating (in this period, cells use external gas as energy), it use the waste of as fuel. This system produces crude oil, electricity and gas with a stable operation mode. When the remaining gas and syngas are added to the counting of the original ratio, a net energy ratio is yielded: consumption of every unit od energy produces 18 units of energy. [9] As shown in Figure 9. 


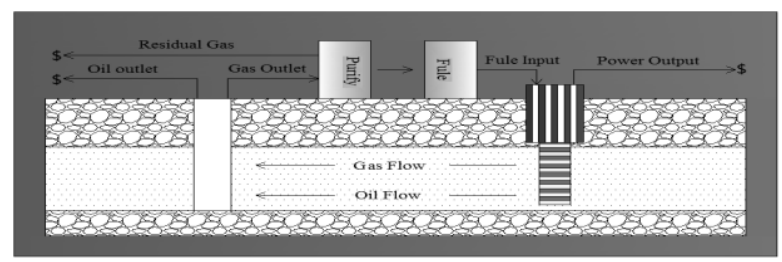

Fig 9 Geothermic fuel cell

\section{Electic heating system}

Thanks to IEP, the temperature is homogenized, and the ratio of anisotropic expansion remains the same. Therefore, within concentric ring as the annular volume expands outside; its perimeter will enlarge with cycle-heating mode. Inserting heating can decrease the thermal expansion of external layer. As picture 5 illustrates.

\section{Advangtage}

(1)Temperature is well-distributed by conduction heating. (2) Porosity and permeability are increased. (3) Energy consumption is self-efficient. (4) Operating cost is lower. (5) It is environmental friendly.

\section{CONCLUSION}

According to the Exxon Mobil Company's data, compared with the well heater, the planar heater requires fewer wells and uses less land. But the movability of hydrocarbons is low and the hydrocarbons are hard to extract, leading to low recycling rate. Same to the Shell's technology, the Exxon Mobil also needs effective measures to avoid the invasion of stratum water and to keep the stratum water from the produced carbohydrate and other ingredients' pollution. Its voltage crack craft increases the permeability of the shale formation. It uses the plane source linear heat conduction, which effectively improves the efficiency of heating. The IEP's energy of geothermal fuel is self-sufficient. The heating uses solid heat conduction to conduct the heat, which greatly improves the heating spread and the utilization rate. What's more, these three kinds of technology all need plenty of electricity to provide heating settlement.

According to the principal of in situ mining electric heating technology and the result of field test, in situ mining electric heating technology has its features as following: (1) It heats the rock layer, the speed is small, and it adds energy consumption;(2) There is no need to heat insulation for the pit shaft, which greatly brings down the cost;(3) Electric heating is complex, it is hard to avoid breakdowns;(4) The design and development of heating wells need to be further studied;(5) The migration motive of hydrocarbons is small, and the recycling rate is very low.

From the development of the oil shale retorting technology, field test has proved in situ electrical heating technique practicable and it has a good prospect. Although this technology hasn't been tested on the commercial scale, it has its own advantages that other heating technologies can't match. The trend of the development of In situ mining electric heating technology is mainly shown in the following aspects: (1) Simplify the process; (2) Expand scale, reduce costs, improve productivity; (3) Combined application of interpenetrated and integrated technologies such as shale paralysis technology of high temperature, temperature control, shale oil and gas gathering and transportation, information control and insulation.

\section{ACKNOWLEDGE}

This research work is supported by Doctor Fund of Liaoning Shihua University (No. 2012XJJ-011).

\section{This heading is not assigned a number.}

\section{REFERENCES}

\section{Journal Papers:}

[1] Zhao jun-Liu. China oil shale [M]. Beijing: Petroleum Industry Publishing House. 2012, 2: 14-28.

[2] Liu zhao-jun,Dong qing-shui. Situation of oil shale resources in China [J]. Journal of Jilin University: Earth Science Edition, 2006, 36(6): 869-873.

[3] Adam R. Brandt. Converting Green River oil shale to liquid fuels with the Shell in-situ conversion process: energy inputs and greenhouse gas emissions [M]. Energy and Resources Group University of California, Berkeley. 2007.

[4] Niu ji-hui, Cen dian-yi. Foreign underground mining methods of the oil shale [J]. Journal of Jilin University: Earth Science Edition, 2006, 36(6):1027-1030

[5] Yang chen, Zhao jing. In-situ electrical heating oil shale oil extraction technology and numerical analysis [J]. Taiyuan University of Technology.

[6] Schlumberger. Field of new technologies [M]. 2010, 22

[7] Huang Zhi-xin. Oil shale development technology in [J]. Resources \& Industries.2010, 6: 22-25.

[8] Fang chao-he, Zheng de-wen. Shell ICP field test [R]. Beijing: Petrochemical Design Institute. 2006.

[9] Zhang li-ping, Zeng rong-shu. Effects of comprehensive utilization of oil shale o n surrounding environment [J]. Coal geology o $\mathrm{f}$ china. 2006, 18(2):46-51 